\title{
EL TIEMPO DEL «PROGRESO» ${ }^{1}$
}

\section{INTRODUCCIÓN}

\subsection{Objeto y perspectiva culturales}

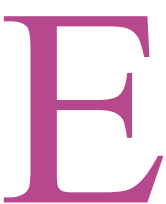

s característico de nuestro modo de concebir el mundo que la determinación de qué sea un objeto de él se realice ineludiblemente desde una determinada perspectiva. Objetos y perspectiva se precisan en alto grado en el modo de pensar que llamamos científico: así, un ente cualquiera -estas líneas, unas palabras-puede ser tematizado diferenciadamente desde perspectivas específicas (la psicológica, la física, la estética, la antropológica... ), convirtiéndose en objetos intelectuales distintos y siendo esta diferenciación una consecuencia del punto de vista o perspectiva formal que se adopte.

Sabemos también que el modo de ver el mundo en general no es uno, único, para todo el linaje de las generaciones humanas. Nosotros compartimos la perspectiva general de nuestros contemporáneos, el modo hegemónico en cada época de ver el mundo, en la medida en que compartimos un lenguaje común. Modo que nunca está hecho del todo y que cambia tan imperceptible como interactivamente. O perspectiva que no está exenta, por otra parte, de ambigüedad y confusión, aunque sólo fuera porque en lo que contempla, el mundo en general, se incluye tanto lo que hay como lo que se sueña de verdad, la ontología y la ética.

De modo que esa perspectiva común tiene rasgos babélicos: es en realidad un conjunto de perspectivas más o menos dominantes, más o menos subalternas, que no impiden enteramente la

${ }^{1}$ Texto de una conferencia correspondiente al ciclo sobre La Modernitat organizado por el Centre d'Estudis de Temes Contemporanis de la Generalitat de Catalunya. Barcelona, 22 de noviembre de 1990. 
comunicación en el obrar ni el obrar mismo, aunque la Torre que resulta de ese obrar puede carecer de sentido, de plano común.

\subsection{Cómputo, percepción y concepción del tiempo}

Respecto del tiempo, esa categoría fundamental de nuestra experiencia, podemos realizar intelectualmente alguna de las siguientes operaciones: contarlo (o, como suele decirse ahora, algo bárbaramente, computarlo), percibirlo, y también concebirlo. Los modos de contar el tiempo, de percibirlo y de concebirlo son culturales, históricos.

El carácter histórico del cómputo del tiempo es evidente: ahí está lo diverso de los instrumentos de medición: del reloj solar, de agua o de arena al cronómetro informatizado (del mundo del «más o menos» al universo de la precisión), por no hablar de los modos de contarlo, instrumentales como los mencionados o simplemente contemplativos (la sucesión del día y de la noche, de las fases lunares, de las estaciones). No nos ocuparemos de los problemas relativos a la medición del tiempo, aunque indirectamente tienen que ver con nuestro tema. El carácter histórico de la percepción del tiempo -es decir, el variable modo histórico en que se correlaciona su paso con la experiencia humana- es en cambio asunto distinto: no suele pararse mientes en él, pero los historiadores y antropólogos nos han proporcionado excelentes filmaciones intelectuales ${ }^{2}$ de su diversidad cultural e histórica. Gracias a ellas es posible vincular las percepciones históricas del tiempo a las diversas prácticas sociales; así, podemos entender que la percepción del tiempo va ritmada con la actividad social e individual, y que, consiguientemente, culturas basadas en actividades distintas, o incluso de actividades tecnológicamente diferenciadas, ritman diversamente ( $\mathrm{p}$. ej., expresiones como «más tarde», «en seguida», etc., son significativas de períodos de tiempo de muy distinta duración en diferentes culturas).

Más abstracta que la percepción del tiempo es su concepción. Pues la concepción del tiempo es en realidad la perspectiva desde la cual éste es percibido, y tiene que ver con el sentido cultural del tiempo como objeto o, dicho de otra manera, con la inserción

${ }^{2}$ Como E. P. Thompson, «Time, Work-discipline and Industrial Capitalism», en Past and Present, 1967, 38; trad. cast. en Tradición, revuelta y consciencia de clase, Barcelona, Crítica, 1979. 
de éste en la metafísica o concepción del mundo hegemónica de una cultura, en una sociedad: una metafísica que afecta, por lo común, a no pocas generaciones (pero que, no se olvide, puede contener subculturas y poseer los rasgos babélicos antes aludidos).

\section{CONCEPCIONES HISTÓRICAS DEL TIEMPO}

Las principales concepciones históricas del tiempo son la del tiempo cíclico y las distintas variantes de la concepción lineal (los tiempos de espera, el tiempo del progreso) -en realidad variantes, a su vez, del tiempo cíclico, o tiempo cíclico olvidado de su origen-. A las que hay que añadir el tiempo del Mesías. Aquí se aludirá separadamente a todas ellas, pero no ha de olvidarse -repito- que muchas culturas del linaje humano han sido más o menos babélicas; que incluso hoy cabe encontrar en no pocos posesos del tiempo del progreso restos vivientes, actuantes, de la concepción cíclica del tiempo. Es el tributo esquizofrénico pagado por una cultura insegura de sí.

\subsection{El tiempo cíclico}

La concepción del tiempo que se expresa con la metáfora del círculo ha sido probablemente la más duradera y abarcante de las sostenidas por la humanidad. En cierto modo el movimiento circular es la imagen visual de la pulsación, de lo rítmico.

El tiempo concebido circularmente simboliza la reaparición de acontecimientos esencialmente idénticos. Se basa en las pulsiones rítmicas de la Naturaleza: el «ciclo» de las estaciones, del día y la noche, de la menstruación, de las marcas, de las fases de la luna, de los nacimientos y las muertes. Concepción identificada seguramente con el cómputo primitivo del tiempo -períodos más largos que los nuestros en la vida cotidiana-, con los más notorios ritmos naturales, a los que es preciso adaptar la actividad humana en sociedades cazadoras o pescadoras, recolectoras y agrícolas.

La concepción cíclica del tiempo puede alimentar incluso la metafísica del «eterno retorno», la creencia en la migración de

${ }^{3}$ En la plenitud del tiempo «del progreso», las publicaciones periódicas de masas aparecen cargadas de horóscopos -residuos culturales pervertidos de la concepción cíclica del tiempo. 
los espíritus: todo, hasta la vida del propio espíritu, vuelve a empezar. Aun sin esta creencia, la Naturaleza, señora del tiempo, se presenta encantada, sacralizada. Pues también esa Naturaleza «esencialmente» rítmica es imprevisible: la tormenta, la inundación, el rayo y el incendio, el temblor de la tierra y la erupción del volcán -para un universo que sólo concibe la causalidad y aún no la estadística-. Lo arrítmico es causa de calamidad: mal, castigo; se personifica en agentes invisibles, al igual que lo rítmico y casi siempre, por conocido, bueno. El universo es sagrado, está lleno de signos, de indicios que apuntan al Misterio. El tiempo cíclico se halla poblado de deidades, acaso pequeñas, pero más poderosas que el hombre, ya que obran lo que no está al alcance de éste.

El tiempo sagrado es siempre un tiempo cíclico porque es indispensable repristinar el momento de perfección originaria, el momento en que se narra el «mito fundacional» de una cultura ${ }^{4}$. Los pueblos están convencidos de que «en los orígenes» se dio el «tiempo verdadero»-antes de la caída, o la edad de oro (o la versión idealizada del comunismo primitivo)- del que se ha salido por un mal o una culpa, generalmente de alguien extraño al grupo. Lo sagrado es, en este contexto, repristinación de la vida, o sea, eliminación de la muerte, vida eterna. El tiempo es cíclico en la concepción cósmica, total. En la vida histórica puede ser, sin embargo, una espera lineal y vacía.

Las culturas imbuidas de la concepción cíclica del tiempo son culturas, por decirlo con la expresión habitual, «basadas en la tradición». Quienes viven en ellas conocen «lo que siempre ha sido», obran lo que se ha obrado siempre. El papel del recuerdo es estabilizador, restaura el pasado en el presente. El futuro se contempla con esperanza y con temor, pero está en lo esencial, predeterminado, y por tanto puede ser objeto de predicción, puede ser conocido por medios adivinatorios especiales.

El conocimiento [de la naturaleza, del futuro] proporciona poder: el de los magos, en comunicación con lo sagrado. Los sacerdotes del antiguo Egipto, capaces de prever con precisión la inundación estacional del Nilo que anega los campos, o los eclipses, y los sacerdotes mayas, conocedores exclusivos del calendario, culminan una historia precedente por su capacidad de incidencia sobre una actividad social esencialmente agrícola.

La inevitabilidad del ciclo está por encima de los acontecimientos. Así aparece en la fuente débil de nuestra cultura: la fuente griega. Para Herodoto, la historia muestra una norma

${ }^{4}$ M. Eliade, Lo sagrado y lo profano, Madrid, Guadarrama, 1981. 
que se repite, que está regulada por la ley cósmica de la compensación; la némesis restaura periódicamente el equilibrio entre fuerzas históricas contrarías. Y Tucídides, por su parte, está convencido de que los acontecimientos que han ocurrido en el pasado se producirán de nuevo en el futuro en la misma o semejante forma ${ }^{5}$. Para cierto filosofar antiguo -y no tanto-, los acontecimientos son ruido («Qué descansada vida...»). Así será posible dotar de sentido a todos los instantes de la vida en que se está presente para uno mismo (Epicuro).

\subsection{El tiempo lineal}

En realidad la concepción lineal del tiempo tiene, como veremos, un origen circular. Pero se trata de un círculo tan dilatado, extendido, que no se percibe como tal. Es un tiempo linealmente extenso como una llanura en la tierra: el paisaje se percibe como plano y la trayectoria que lo atraviesa como recta, aunque, en realidad, la trayectoria siga la curvatura inmensa -relativamente al caminante humano- del globo terráqueo.

La concepción lineal del tiempo -del tiempo como una línea extendida, sobre la que se sitúan las vidas de los seres humanos- es la propia de la concepción judeo-cristiana del mundo. En ella la Naturaleza queda relegada a un segundo plano: el primero lo ocupan acontecimientos reales o del imaginario colectivo. No hay retorno posible al pasado tal como fue conocido. El futuro ocupa tendencialmente su lugar. El tiempo lineal es esencialmente tiempo de espera. De espera tendida entre dos acontecimientos escatológicos puntuales.

La concepción lineal del tiempo se inserta en concepciones del mundo diversas.

\subsubsection{El tiempo lineal como tiempo de espera}

En la concepción judaica, teocrática, del mundo, el tiempo es esencialmente tiempo de espera del Mesías. Se espera el cumplimiento de la promesa de Dios al pueblo elegido, al linaje favorito. Ese acontecimiento, que se sitúa en un futuro indeterminado, que escapa totalmente a la voluntad de los seres humanos, dilata el círculo y lo convierte en línea. Nada que se repita es comparable

${ }^{5}$ Vid. K. Löwith, El sentido de la historia [1954], Madrid, Aguilar, 1968. pág. 18. 
al Acontecimiento: único, esperado, irrepetible. En el interior de esa concepción del mundo no cabe sino la espera. El tiempo de la espera es un tiempo vacio, pues su sentido está precisamente en la espera. Las cosas de la antropología se subordinan a las cosas de la teología. La espera vacía es sin embargo sagrada: pues en cualquiera de sus instantes puede aparecer el Mesías como Redentor, dotando de sentido al vacío tiempo de la espera, y como vencedor del Mal, cuyo triunfo actual -en el mundo de la caída, de la culpa-carece de valor porque se considera efímero. Es el absoluto encantamiento del mundo.

El tiempo de la tradición cristiana no altera el fondo de las cosas: pues la llegada del Mesías que fue rechazado, asesinado, por los hombres, no cambió el mundo: no instauró el reinado de la paz, de la fraternidad, del amor. De la eliminación de la muerte. La Redención no es de este mundo, sino de otro, de una vida otra. El tiempo de este mundo es tiempo de espera de otra vida. Para el misticismo cristiano el tiempo no es verdadero tiempo, carece de sentido actual: «Vivo sin vivir en mí.» Es tiempo de espera de la gracia: nisi iustus est securus, ni siquiera el justo está seguro el Día de la Ira, que pone fin a la espera. La gracia (procedente de Dios) sólo se puede, asimismo, esperar: no está «dada de antemano». El sentido específico del cristianismo es que llena la espera de obras, sin embargo. No basta ser del linaje, no basta tener la fe del linaje para ver cumplida la promesa de vida eterna: la fe sin obras es un cadáver.

En la tradición estrictamente cristiana, aunque el futuro es definido por la voluntad divina, lo determina la voluntad personal, nunca la fatalidad. El hombre no puede prever el futuro salvo que le sea revelado por Dios. Como señala Löwith ${ }^{6}$, el sentimiento ante el futuro viene a ser de indecisión, de vacilación, dada la imposibilidad de calcularlo teoréticamente.

Cierta variante del tiempo cristiano, la propia del calvinismo yankee -el Time is Money, de Benjamin Franklin- es en realidad un tiempo distinto: tiempo de progreso ${ }^{7}$. Pero ello por los particulares teologemas ligados a la doctrina de la predestinación. El tiempo de este mundo sólo sirve para adivinar lo que Dios ya conoce: el predestinado se adivina tal en el mundo, y en el mundano money. Pero esta variante participa de dos mundos: es tiempo «cristiano» $\mathrm{y}$ «tiempo de progreso», pero no puramente

${ }^{6}$ Op. cit., pág. 21.

${ }^{7}$ M. Weber, La ética protestante y el origen del capitalismo [1904], Barcelona, Península, 1969: también en el volumen de escritos de Weber, Ensayos de sociología de la religión. L Madrid. Taurus, 1983. 
en ninguno de los sentidos; le falta una característica básica de la concepción «progresista» del tiempo: la laicidad; y la predestinación le aparta de una característica fundamental del pensamiento cristiano: la teología de la caridad y del sacrificio.

\subsection{Agujeros del tiempo lineal: el tiempo del Mesías}

Hay una concepción del tiempo que, sin ser social, siendo sólo individualmente sostenida, es sin embargo relevante: la concepción mesiánica del tiempo, el tiempo del Mesías. Vale la pena traerla a colación. Naturalmente, sin necesidad de situarnos en el plano de las creencias religiosas. Podemos ocuparnos de las cosas del cielo como de cosas de la Tierra.

Tratemos de situarnos con la razón en el interior de la mente de quien históricamente se proclamó Mesías: en la lógica del Jesús de Nazaret «culturalmente influyente» [que puede no coincidir exactamente con la persona histórica que está en su base].

Necesariamente hubo de partir de una concepción lineal del tiempo como tiempo de espera: tal era el imaginario colectivo de la época, y por lo que sabemos de la transmisión de las imágenes del mundo, hasta uno u otro momento Jesús de Nazaret hubo de compartir la concepción heredada (probablemente, hasta su escapada a la discusión teológica en el Templo).

Lo específico de Jesús de Nazaret es que comprende enteramente la cultura de su tiempo: una cultura que está a la espera. No se entenderá su obra sin percibir ante todo la profunda consciencia histórica de este rabí. Los materiales de la cultura de la tradición judaica son elementos indispensables para Jesús, que no puede concebirse sin ellos de la misma manera que es impensable una coral de Bach al margen de la tradición musical occidental que llega hasta este compositor. De ahí, también, el poder cultural que tendrá la predicación de Jesús.

Para el pueblo hebreo más que para ningún otro, la religión es la cultura. Recordemos: religión especial de pueblo elegido, en pacto de alianza con Dios extendida a toda la estirpe y renovado a través de la circuncisión de los varones, con la promesa de un Mesías redentor por parte de la divinidad. La concepción del tiempo es una de esas estructuras portantes de lo sagrado. El tiempo de Jesús de Nazaret que parte de y está en la tradición judaica es sin duda un tiempo lineal, remoto en el pasado y lejanísimo en el futuro de espera del Mesías. Pero el Jesús de Nazaret que llega a comprender como tarea suya no seguir la tradición y las Escrituras sino darles su cumplimiento ya no está en 
esa cultura, sino fuera de ella ${ }^{8}$. El tiempo de espera quedará abolido -cree- si el Mesías ha llegado ya. Jesús de Nazaret afirma que la hora de la salvación ha llegado porque no es la del retorno de un profeta, no es la hora de un acontecimiento excepcional: es una hora cualquiera. Al proclamarlo decide el final del tiempo de espera fundamental de la tradición judaica. Y abre el tiempo del obrar. Abre un agujero en el tiempo -tal como es culturalmente concebido- y pasa a otro distinto por el resquicio abierto.

El Mesías atraviesa el tiempo. Percibe la debilidad de un punto de la clausura cultural del imaginario colectivo, actúa sobre él y alumbra otra cultura. Ha entrevisto la posibilidad de inaugurar otra cultura.

«Sólo el Mesías mismo consuma todo suceder histórico, y precisamente en el sentido de crear, redimir, consumar su relación para con lo mesiánico.»-escribirá W. Benjamin en su Fragmento teológico-político 9 .

En una época en que está de moda hacer escarnio del mesianismo de los oprimidos no está de más ver que la operación de este Mesías, su sacrificio, tuvo históricamente cierto éxito pese a no inaugurar la era de la fraternidad -esto es, si lo entendemos como mediador histórico y no teológico-. No todo es ideología en el mesianismo ni cualquier mesianismo vale.

Es mesías quien abre paso de una concepción del tiempo a otra. Hace camino al andar de uno a otro tiempo. Se halla en dos tiempos distintos que sólo diferencia él -una hermosa manera de entender que cualquiera de los instantes de la vida podía ser, como quería la tradición, el de la llegada del Mesías. Jesús de Nazaret existe en el tiempo que va a cerrar, pero piensa, siente y obra en el tiempo nuevo. En la acción, los momentos de ruptura de la tradición son para él norma, no excepción (asunto que los discípulos no comprenden bien). Jesús acaba con la fe pasiva y pretende universalizar la nueva cultura del amor fraterno a todas las gentes (no hay para él un pueblo particularmente elegido). La innovación cultural es completa, aunque se exprese al menos parcialmente con las metáforas de la tradición heredada -como por otra parte es inevitable para lograr una comunicación eficazmente intersubjetiva.

${ }^{8}$ Ida Magli, Gesù di Nazaret. Tabú e trasgressione, Milano, Rizzoli, 1982, pág. 19.

${ }^{9}$ Este texto, de 1920 ó 1921, se halla traducido al castellano por J. Aguirre (quien lo fecha erróneamente en 1940), en W. Benjamin, Discursos interrumpidos, I, Madrid, Taurus, 1973. 


\section{EL TIEMPO ACELERADO DEL «PROGRESO»}

El tiempo del «progreso» es el tiempo específicamente moderno. Propongo examinarlo siguiendo pasos analíticos diferenciados. En primer lugar se verán sus rasgos genéricos, junto con alguna de las concepciones especiales, sectoriales, como la del tiempo de antes de la Revolución, para analizar luego los rasgos del tiempo acelerado del «progreso» que constituye la concepción del tiempo hegemónica en el presente presentando algunas observaciones críticas a los rasgos comúnmente admitidos de esta concepción.

\subsection{Los rasgos genéricos de la concepción moderna del tiempo: el «progreso»}

La Ilustración es la Edad de la Razón. Todo es susceptible de racionalización: en primer lugar, de medición. El nuevo sistema social, capitalista, que en un proceso secular se sobrepone al feudalismo espolea la aplicación de la razón al ámbito productivo. De la racionalidad productiva nacerán el maquinismo y la gran industria, lo que llegará a llamarse la racionalidad tecnológica. La nueva sociedad recurrirá a la razón para dar una legitimación profana del poder en el ámbito político: el Estado laico, el soberano popular (Qui vote règne, decía $\mathrm{V}$. Hugo), tras un largo proceso en el que el demos pugna por la conquista de su propia existencia política, por sus derechos políticos. De estos cambios nace una nueva concepción del tiempo, la creencia en la posibilidad de un sentido profano de la historia -no ya un sentido escatológico sagrado-, sentido que se ve precisamente en progresar, en mejorar gradualmente, por pasos, la situación del ser humano en el mundo.

Esta nueva concepción del tiempo, que encuentra un sentido en la historia, es la concepción del tiempo del progreso. Una concepción que penetra socialmente la modernidad, que se instala en la Ilustración, pero que sólo en tiempos muy recientes ha llegado a la plenitud de su hegemonía. Merece la pena detenerse en algunos de los elementos constituyentes de este aspecto del mito fundacional de nuestra propia cultura.

La nueva concepción del tiempo se asienta sobre un hecho real: la acrecentada capacidad humana para la obtención de medios de vida y de medios para la obtención de medios de vida. La creciente capacidad tecnológica, que hace posible la obtención de más medios con disminución de costos temporales y materiales 
-al menos teóricamente- es la base objetiva sobre la que se asentará la idea mítica del «progreso». Es la base de la creencia en mejorar característicamente ilustrada.

Esta creencia, de todos modos, de una parte no se detiene a pensar que los nuevos conocimientos y destrezas son también la base real de la creciente capacidad destructiva de la humanidad y el medio de destrucciones reales, que considera como costes: los famosos «costes del progreso». De otra parte, esta creencia tiende a ver sobre todo el crecimiento de la capacidad productiva y no tanto los efectos de ese crecimiento productivo sobre los productores en el sistema social realmente existente.

Un segundo elemento contribuye a fijar el cambio como «progreso»: la nueva racionalidad científica se expande a ámbitos de la vida social distintos del productivo. En el ámbito económico -el de las relaciones para producir, no el de la producción misma- se asienta la idea de que la persecución de los fines particulares no es incompatible con la felicidad pública, con el bien general. Aunque tras los fines particulares se halle el egoísmo privado, el crecimiento productivo es visto como bien común: los vicios privados producen la pública virtud. Este milagro, satirizado por Mandeville pero aun hoy creencia dominante, permite trasladar la idea de mejoramiento -implícita en la de crecimiento, aunque siempre con un punto oscuro, dudoso- del ámbito productivo al ámbito social general. No sólo crecimiento: también mejoramiento social.

La transformación cultural y política harán el resto. La distancia que gradualmente se establece entre la sociedad industrial y la preindustrial, manifiesta tras la Revolución francesa, con innovaciones fundamentales en los aspectos políticos y jurídicos de la existencia social, por no mencionar los culturales -de los que el sistema métrico decimal resulta emblemático-, será objeto de un nuevo culto en las exposiciones universales de la industria.

Con el «progreso» se establece un sentido de la continuidad histórica. La Revolución francesa citaba a la Roma antigua -p. ej., en sus fiestas, en su calendario, en las denominaciones de los cargos públicos-; esa cita se convierte luego en (falso) antecedente: el hundimiento civilizatorio que siguió a la caída del Imperio romano pierde sentido hasta ser olvidado fuera de los ámbitos académicos; en el saber común se instala un continuum histórico.

Por último, la traslación de las ideas biológicas de Darwin al plano de la historia, al plano social, hará el resto. También la historia se concibe como supervivencia de lo mejor y muerte de lo peor. 
En suma, el mito del progreso se resume en la idea de un perfeccionamiento gradual, por pasos, cuyo sujeto es la humanidad -no mero progreso de sus destrezas, de sus saberes, sino del sujeto de estos-; el perfeccionamiento se concibe como interminable -como se considera interminable la acumulación del capital-; y se trata, finalmente, de un proceso concebido como incesante, sin rupturas. La idea de «progreso» pasa de ser una expresión descriptiva de un fenómeno material y objetivo a tener un sentido moral, proyectivo, respecto de la humanidad misma, aunque no exija ningún comportamiento particular. Su sentido moral es más bien apologético de la realidad.

Es precisamente en el plano moral donde la ilusión del imaginario colectivo muestra su lado débil. La época «del progreso» ha visto desaparecer cierta barbarie de la vida pública -de esa mejora es testimonio el derecho penal ilustrado-, pero en ella la humanidad ha obtenido la capacidad del genocidio instantáneo. El «progreso» es fundamentalmente de una capacidad material omnidireccional: también en la dirección de la barbarie y del exterminio.

El «imperativo categórico del crecimiento», del que habla Marramao ${ }^{10}$, la norma básica de las sociedades capitalistas, no se aplica en el plano moral. Pero acelera la historia. El tiempo en aceleración del progreso es nuestro propio tiempo. Esta concepción ha experimentado recientemente ciertas alteraciones; antes de examinarlas conviene, sin embargo, aludir a la escatología del «progreso»: El Tiempo de la Revolución o, más precisamente, el Tiempo de Antes de la Revolución.

\subsection{Excurso: El tiempo de «antes de la Revolución»}

Desde un punto de vista histórico hay que considerar este tiempo -esta concepción del tiempo- como una subcultura especial del tiempo del progreso. El tiempo de «antes de» la Revolución está inserto en el tiempo del progreso. Es por ello esencialmente babélico.

La Revolución, vista como acontecimiento que inicia «la ciudad futura» y pone fin a la prehistoria humana, la Revolución escatológicamente concebida, es un acontecimiento -o un conglomerado serial de acontecimientos internamente vinculados- único. El Acontecimiento que previsto en un imaginario colectivo

198.

${ }^{10}$ G. Marramao, Poder y secularización, [1983]. trad. cast. Barcelona, Península, 1989, pág. 
crea un antes de la Revolución y un después de la Revolución. El tiempo de antes de la Revolución tiene un componente moral positivo, activo, a diferencia del tiempo del progreso -en el que simplemente se está- pues sólo hay tiempo de antes de la Revolución si se quiere idealmente la Revolución, si se está por ella.

Es un especial tiempo de espera. Pues, aunque sólo en parte, es tiempo de acercar el Acontecimiento, de crear sus condiciones subjetivas, que solía decirse. ¿Por qué sólo en parte tiempo de espera? Porque a menudo, y con independencia de la concepción escatológico-revolucionaria que les preste sentido, esos instantes temporales que se ven como de antes de la Revolución son objetivamente instantes de defensa de la vida y de la dignidad humanas frente a agresiones degradantes. [Los comunistas soviéticos, que sacrificaron todo contra el nazismo bajo Stalin, ilusoriamente creían construir la ciudad futura mientras libraban objetivamente a la humanidad de una barbarie.] La Torre de Babel despunta también desde esta perspectiva.

¿Por qué tiempo de espera especial? Porque el Acontecimiento, en esta escatología, no puede producirse sin el concurso de los que lo esperan -si bien no depende solamente de ellos: también de las llamadas por la doctrina causas objetivas. La espera es más cristiana que judaica, pues se trata de una espera activa. Esta espera activa recibe el nombre de praxis, y está internamente amenazada por la impaciencia revolucionaria que olvida la objetividad, la inserción en el mundo de lo posible. Por otra parte, como diría Walter Benjamin $^{11}$, se creía «nadar con la corriente», esto es, que las causas objetivas tendían a aproximar el Acontecimiento Revolucionario.

\subsection{Una censura en el tiempo del progreso: exacerbación y crisis}

Sin querer entrar en polémicas, ya bastante especializadas, acerca de la Modernidad, sí deseo apuntar que se ha producido en tiempos recientes una cesura histórica que puede tener consecuencias sobre la clausura cultural del imaginario colectivo y en particular sobre la concepción progresista del tiempo. Esta cesura se percibe, respecto del tiempo tal como es concebido, como una aceleración del mismo, como una progresión acelerada, exacerbada,

${ }^{11}$ W. Benjamin, Sobre la historia, cit. 
y puede contemplarse desde muy variados puntos de vista, lo cual da idea de su complejidad.

Desde el punto de vista económico, se trata de la crisis de las políticas keynesianas y la implantación de modelos de política económica neoliberales o mixtos poniendo fin a una época de «bienestar», o de crecimiento económico con redistribución en favor de salarios. Desde el punto de vista tecnológico, se implantan innovaciones ya anticipadas desde los años treinta y cuarenta, pero introducidas ahora en la vida productiva: la robotización informática, la biotecnología, la nueva tecnociencia química y los nuevos materiales son innovaciones tecnológicas importantes. Desde el punto de vista ideológico, se ha disuelto prácticamente la concepción escatológica «profana» de la revolución. Desde el punto de vista político, se manifiesta la crisis de la forma partido como instrumento de mediación política, la crisis de la forma estado como soberana. Desde el punto de vista económico de nuevo, se da la mundialización práctica de la economía dirigida por empresas multinacionales. Desde el punto de vista ecológico, la cesura consiste precisamente en la aparición de este punto de vista como necesario cuando menos para la consideración de la crisis del industrialismo, etc...

Esta cesura no puede fecharse con exactitud, pues no todos los estratos de la vida social han mutado o se han desplazado simultáneamente y, sobre todo, porque no está claro todavía cuáles han de ser los rasgos del mundo emergente que resultarán más cargados de consecuencias para el futuro.

Los rasgos más destacables de la sociedad que surge tras esta cesura son los siguientes:

1. Se pasa de la acumulación de capacidad transformadora localizada a la capacidad transformadora general. La crisis de los setenta abre «nuevos tiempos» en el sentido de que la innovación productiva deja de depender de tal o cual esfuerzo particular y pasa a basarse sobre todo en la capacidad productiva ambiental general ya lograda por la humanidad en las zonas altamente industrializadas del planeta, en la presencia generalizada de conocimientos y destrezas que exigen años de cultivo fuera de la vida productiva- en amplios sectores de la población, capaz de manejar un instrumental de alto contenido científico en formas rutinarias.

2. Aparición de nuevas tecnologías y de un grado muy elevado de producción y consumo en una economía que conserva la forma mercantil privatizada. Estas tecnologización del mundo presenta riesgos de dos tipos: 
a) político-sociales: pueden ser la base de un nuevo totalitarismo tecnológicamente fundamentado -basta pensar, p. ej., en la biotecnología, por la cual el universo de Un mundo feliz de Huxley se convierte en una posibilidad real y no en mera imaginación; en la robotización, etc.

b) Ecológicos: junto con el crecimiento exponencial de la población, los problemas tecnológicos derivados -de tipo energético, de recursos, de residuos, de materias primas, etc.- hacen previsible una crisis de la relación del hombre con el medio.

3. El mundo se divide manifiestamente en dos universos interdependientes pero diferenciados: a) el industrializado -con poca población y altos recursos científicos, técnicos, industriales, etc., relativamente a $b$ ): el mundo del infradesarrollo, un mundo de pobreza, de exceso demográfico, de escasos recursos. Y se empieza a cobrar consciencia de la dificultad de la universalización sin cambios del modelo de vida del mundo rico, de la mera extensión de sus modos de existencia al mundo que vive en la pobreza, sin suscitar un ulterior deterioro de los problemas ecológicos del planeta.

Todo ello sin hablar de lo que se vive como una aceleración al parecer sin precedentes de los acontecimientos históricos.

\section{LA PERCEPCIÓN SOCIAL DEL CAMBIO EN EL «PROGRESO»}

La percepción por las gentes de estos cambios ha determinado una actitud que puede considerarse nueva en su concepción del tiempo. Se trata de un cambio drástico en la manera específica de considerar el pasado histórico y una posición diferente de la mantenida por las generaciones anteriores ante el futuro y también ante el presente.

\subsection{El Pasado}

La tradición, el conjunto de costumbres y creencias sociales heredado, parece ahora incapaz de esclarecer los comportamientos; el pasado, excesivamente distinto del presente y por supuesto del futuro, no es considerado como un elemento de referencia digno de confianza. Los tiempos parecen cada vez más distintos a cualquier precedente. Algunos filósofos califican a este fenómeno de reducción del ámbito de la experiencia.

Con ello quieren significar que la experiencia social se ve 
profundamente limitada. La transmisión de conocimientos ya adquiridos y de modos de enfrentarse a situaciones conocidas (el aprendizaje de mantenimiento de lo ya conocido por generaciones anteriores, que es en realidad un conjunto de saberes y reglas para hacer frente a situaciones de las que se tiene experiencia) cede importancia a la más acuciante cuestión de la capacidad de enfrentarse a hechos sin precedentes y a situaciones desconocidas (aprendizaje innovador, para afrontar situaciones de las que no se tiene experiencia; un aprendizaje que, sin embargo, no se socializa e institucionaliza como el de mantenimiento, viviéndose su problemática de manera individual) ${ }^{12}$. La transmisión de modelos intergeneraciones de comportamiento se va vaciando de sentido o de importancia relativa. El aprendizaje real se realiza cada vez más substancialmente por shock: por el trauma que origina la situación nueva. De ahí el desprecio algo irreflexivo por lo que se denomina la tradición.

\subsection{El futuro}

Pero, por otra parte, una característica del actual «progreso» es la desaparición de la esperanza escatológica, que ha sido parte integrante de la actitud tradicional para la consideración del futuro.

Muchas gentes han perdido, aunque sólo en la zona altamente industrializada de la Tierra, en el -llamémosle- Occidente «adelantado», la fe religiosa (y aun contradictoriamente, como se verá más adelante). Dios ha muerto en el imaginario colectivo. Para estas gentes las metafísicas de tipo manifiestamente religioso son creencias inactivas. Muchas personas no se representan su propia existencia como un paso previo para una vida otra. Lo cual significa que no están dispuestas a sacrificar su vida real en función de tal concepto. Su proyección temporal se reduce a la propia vida biológica y, a cuanto la afecta.

También se van abandonando los valores ligados al futuro como tiempo de espera de la Revolución (la esperanza, el coraje, la solidaridad, el humor) o del Reino de los Cielos (la piedad, la compasión, la caridad, que ayudaba a soportar la enfermedad, el dolor, la vejez). Se pierden desde la tensión revolucionaria hasta el sentimiento de que el Reino de Dios está cerca.

${ }^{12}$ Los conceptos de «aprendizaje de mantenimiento» y «aprendizaje innovador» están tomados del Informe al Club de Roma Aprender, horizonte sin límites (trad. cast. Madrid, Ed. Santillana). 
De ahí un «redimensionamiento» del concepto mismo de futuro. Este no es ya un Futuro metafísico (al que en sociedades menos «progresistas» podía sacrificarse la vida entera). El «futuro» del tiempo del «progreso» contemporáneo es meramente un futuro de vida en la tierra para cada generación, un futuro desencantado. Ahora bien: atendida la velocidad de los cambios, incluso este futuro parece imprevisible. Algunos filósofos llaman a esto disminución del horizonte de las expectativas ${ }^{13}$. Las gentes perciben cada vez menos qué pueden esperar, e incluso dejan de confiar en la probabilidad de expectativas razonables (estamos lejos de la época anterior a la primera gran guerra, cuando los funcionarios recién escalafonados tomaban nota de la fecha exacta en la que se produciría su jubilación cincuenta o más años más tarde); por ello se manifiesta una tendencia (en el ámbito sociocultural apuntado) a dejar de hacer previsiones individuales para el futuro.

Y si se produce una pérdida de previsiones, de representabilidad del futuro, la consecuencia casi automática es la pérdida de la disposición a sacrificar el presente a un futuro mejor cualquiera. Una pérdida de capacidad proyectiva y de volición del futuro ${ }^{14}$.

El resultado es una contradictoria, esquizofrénica desaparición del interés por el futuro en seres humanos para quienes el presente puede ser difícilmente soportable. El ambiguo No future de los jóvenes, en lo que hay probablemente más de histérica apología del presente y de colonización de la consciencia por la industria de masas que de percepción de la dificultad del futuro.

Esquizofrenia, pues, ante el futuro. La necesidad de preverlo se agudiza, pero también se desmotiva al parecer fuera de control. El «progreso», como barruntaba Keynes, ha engendrado una contraposición entre sus resultados y la capacidad de proyectar el futuro. Y desde el punto de vista ecológico, que ha resultado ser fundamental, la sociedad occidental, que le ha dado a su crecimiento un «sentido histórico progresista», se encuentra ante el hecho de que su «desarrollo» mismo es contrafinalístico ${ }^{15}$.

${ }^{13}$ Así, R. Bodei, «Attualità e tempo dell'attesa: strategie per pensare il futuro», in IRIDE, 2, enero-junio, 1989, págs. 123-133. La expresión, sin embargo, procede de R. Koselleck en 1959.

${ }^{14}$ Ello puede dar una clave de la creciente apoliticidad de las sociedades: pues los proyectos políticos implican siempre de algún modo sacrificio del presente en función del proyecto para el futuro; en este sentido, p. ej., Salvatore Veca, Cinadinanza, Milano, Feltrincili, 1990.

${ }^{15}$ Vid. G. Marramao, Poder y secularización, cit. cap. VI, 3. 


\subsection{Presente}

\subsubsection{El Presente Transitorio}

La vida se reduce al presente. Pero el presente del tiempo del progreso se caracteriza también contradictoriamente: es siempre transición hacia algo distinto. Estamos aún en la concepción de raíz judeocristiana de que el tiempo sólo tiene sentido una vez consumado (o, en sentido profano, consumido).

En el presente de hoy, la vida biológica, y cuanto la afecta, ha llegado a ser el ámbito a que se reduce el tiempo del progreso. El pasado tiende a volatilizarse, a no servir de referencia; el futuro sigue apareciendo culturalmente -y cada vez más ideológicamentecomo una promesa que, contradictoriamente. tiende a ser la inseguridad misma. Y el tiempo tiende a reducirse al presente porque, por otra parte, desde el interior de la ideología progresista el futuro es visto como esencialmente igual al presente, aunque -sin que se sepa muy bien por qué- mejor.

El presente es siempre un presente transitorio. El presente es siempre todavía no. El presente del progreso acelerado es un presente vacio.

\subsubsection{Contenido del Presente progresista}

Pues, ¿qué ocurre, efectivamente, en el presente de cada vida? ${ }^{16}$

Los rasgos más destacables del modo en que se vive el presente en transición, en el tiempo acelerado del progreso, podrían ser los siguientes:

a) Se da, ante todo, una sobrevaloración del presente inmediato. Un acortamiento de las dimensiones del presente, consecuencia de la inseguridad de los proyectos. Y se tiende, además, a vivir predatoriamente este presente inmediato, a componerlo discontinuamente de consumos, a llenarlo de pequeñas «excepcionalidades» tratando de eliminar continuamente su vacío de proyectos.

Este modo predatorio y no proyectivo, consumista, de vivir el presente es un problema de nuestra civilización. Así, la cultura contemporánea de la droga química -cuyo papel es bastante diferente del que tiene la droga tradicional en las culturas tradicionales-

${ }^{16}$ R. Bodei, «Attualità e tempo dell'attesa: strategie per pensare il futuro», in IRIDE, 2, enero-junio 1989, págs. 123-133. 
se halla en relación con el vacío cultural del presente. La modalidad aproyectiva-consumista se extiende a los ámbitos íntimos de la vida personal (la tendencia a una manera de vivir la sexualidad como entidad en sí misma, consumiéndola haciendo abstracción de otros aspectos de las relaciones interpersonales, puede servir de ejemplo).

b) Creciente disponibilidad de las consciencias individuales a la colonización por la industria de producción de sentimientos de carencia, por los medios de producción y difusión industriales de contenidos de consciencia.

c) Se da también una tendencia a la reconsagración de lo profano: aparece lo que Pasolini ha llamado «la religión del motor» ${ }^{17}$. O bien el «refugio» hacia valores tradicionales, como los de la fe, en las sociedades islámicas (y recientemente también entre nosotros: en la generación joven de la década de los ochenta aparecen más creyentes activos que en la de las dos décadas anteriores). En el mismo orden de cosas hay que situar a los «nacionalismos», como ideologías diferenciadoras y defensivas frente a la mutación cultural del nuevo industrialismo y el capitalismo multinacional mundializado. La interdependencia mundial del trabajo, presidida por el capitalismo, que impone una misma cultura material (manejo de idénticos instrumentos, desde los productivos a los objetos de consumo) en el mundo, se da en ambientes culturales crecientemente babélicos.

Estos me parecen los rasgos que caracterizan el malestar de nuestro presente. Sin embargo, a los individuos les resulta imposible enclaustrarse totalmente en los acontecimientos de su entorno inmediato pese a la destrucción del universo simbólico de nuestra experiencia, pese a la privatización y al conformismo. La componente moral, proyectiva, de los seres humanos, que es tan indispensable biológicamente para ellos como sus instintos ${ }^{18}$, no queda abolida, aunque encuentra dificultades crecientes tanto en el ámbito de la formación de consciencia como en el de la actuación práctica (de ahí algunos de los sucedáneos de moral anteriormente mencionados, cuya función es dar tensión a un presente desguarnecido, invivible por su incompletud).

${ }^{17}$ P. P. Pasolini, «Los mecánicos-tabernáculo» [1969], en El Caos, trad. cast. de Antonio Prometeo Moya, Barcelona, Crítica, 1981.

${ }^{18}$ I. Eibl-Eibesteldt, The Biology of Peace and War, London, Thames \& Hudson, 1979. 


\subsubsection{Antiutopía del presente}

Pese a que algunos sectores del pensamiento filosófico se complacen en centrar su reflexión en la reducción del horizonte de las expectativas, ateniéndose más bien apologéticamente a las tendencias que se manifiestan en el cuerpo social, el futuro no es tan poco imaginable como se pretende.

Pues existen ciertas expectativas obtenidas por los científicos por extrapolación de factores existentes en nuestro presente. Las síntesis de rasgos del futuro basadas en las tendencias actuantes en el presente tienen una historia relativamente larga, que se remonta a los primeros informes del Club de Roma hace ya veinte años. Estas expectativas resultan fiables en cuanto a las tendencias que señalan, aunque algo inseguras respecto de los plazos y ritmos con que éstas se materializarán debido a la multiplicidad e interrelación de las variables en juego. No deben caer en saco roto, pues aunque se refieran al futuro no se trata de profecías: están construidas con los mismos métodos con que se han obtenido los saberes necesarios para que funcionen nuestros aparatos de uso doméstico, los cuales, obviamente, suelen funcionar.

Estas síntesis no permiten el desinterés por el futuro, ya que diseñan una perspectiva que es imposible considerar sin horror.

Un mundo con graves problemas demográficos, energéticos, de recursos y de residuos, con ambiente deteriorado, con multitud de especies, incluso las más evolucionadas, exterminadas por el industrialismo.

Un universo social que pese a todo ello excluye a más de dos tercios de la humanidad existente hoy de un modo de vida esencialmente no universalizable sin un ulterior encarnizamiento de esta problemática.

Un mundo en que las nuevas posibilidades tecnocientíficas de la ingeniería genética, con el presente dominio político-social, pueden hacer realidad los esclavitos épsilon de $A$ brave new world o la dictadura tecnológica total. Un mundo donde armas de potencialidad genocida, pronto al alcance de cualquier estado, sociedad o mafia industrializados, son el instrumento para dirimir las polémicas.

$\mathrm{O}$, más sencillamente, un presente en el que 40 millones de niños morirán de desnutrición durante el último decenio del siglo $\mathrm{XX}^{19}$.

El futuro está realmente -no sólo como representación- en

${ }^{19}$ Según fuentes de Naciones Unidas de 1990. 
el presente. Lo está como causación, como determinación del presente. Se gesta en tiempo-ahora.

Por eso puede decirse que la percepción histórica del «progresismo», de «lo moderno», es cada vez más ideológica. El contrafinalismo del progreso meramente técnico -sin auténtico progreso social y moral- está mostrando ya sus consecuencias. A mi modo de ver, ello hace inevitable un cambio cultural que ha de llevar al museo el concepto mismo de lo «progresista» (junto a lo «idealista» o lo «romántico»). Que haya de sucederle es cosa que no se sabe. 